\section{THE HOSPITAL OF THE FUTURE}

\author{
BY
}

\section{DUNCAN C. L. FITZWILLIAMS, M.D., Сн.M., F.R.C.S.}

There is a saying that the old order changeth, giving place to new ; but change is not always manifest, and in some departments of our civilization it seems, for a time, imperceptible, and then characterized by a period of great activity. One sees this in the builciing of new hospitals. I am not here referring to the style of architecture, though that has changed quite suddenly, but to the internal arrangements and the ideas which pervade them.

Originally, hospitals were charitable institutions founded, for the most part, by religious orders out of pity for the:r fellow men, for the relief of suffering humanityfor those who rotted in the streets, beggars who could no longer beg, men broken in the wars, those in the last stages of disease, and for few else. Shelter and sustenance were of primary importance, and the medical side took second place. Once admitted to the institution the inmates could remain there indefinitely. Gradually through. the ages the almshouse features were lost and the medical side grew until it became the all-important. feature of the institution as we see it to-day.

Lister's discoveries revolutionized hospital organ:zation, and his influence spread far beyond surg:cal confines. It introduced cleanliness everywhere, and ban shed the "smell of new-mown hay " which pervaded the institutions owing to the number of pyaemic cases in the wards. The tiled or terazzo floors, the rounded corners, the -new paint, and the general air of freshness associated with these institutions to-day are all due to Lister's genius. Since those great changes consequent upon his discoveries, we have been experiencing one of those pauses already hinted at. Public health authorities have influenced the water supply, sanitary arrangements, lighting, and other social services, but there has been no great revision of ideas and no marked changes. If we were to ask any of the charitably inclined members of the boards of our institutions what reforms they would recommend, ninetynine out of a hundred would be hard put to it to think of any. In other words, we are quite content with things as they are. But to those who understand the evolution of the hospital another long stride forward is due, and it is t:me that the finger of criticism, or even of scorn, should be pointed at some of our customs. I shall cite two which are anachronisms embodying some of the most barbaric features of the Middle Ages:

\section{Death in Public}

It is customary in our hospitals to allow a patient to die in the public ward. Nothing could be more crude or unnecessary, for surely dying is as private an affair as birth to the patient and his immediate relatives. Imagine the scene in a large ward at night with the darkened lights casting mysterious shadows on the walls, screens round one of the beds, and nurses gliding to and fro as noiselessly as possible, but with evident hurry and anxiety. The deathly silence preserved by the other patients in the ward is broken only too audibly by the strange and horrible noises emitted by the semi-conscious patient. 'Then there is the hurried sending for the house-surgeon, the consultation with the sister outside the screens, in view of everyone except the patient and his friends, the gestures of helplessness and inability to do more which everyone can understand. The oxygen is hurried in by the porter and pushed behind the screen. Silence is broken by a loud hiss which startles all but the dying as the over-anxious nurse turns on the tap a little too vigorously, or the silence is broken in a still more alarming manner by a loud pop as the buckled tube is blown from the end of the cylinder. Every noise is multipl:ed a thousandfold by the tension of the nerves of the listeners. The sounds from behind the screens become fainter and fainter till at last the silence is broken only by the sobs of the relatives. Later there are the almost silent flittings of the nurse behind the screens as she performs the necessary last rites, and lastly the arrival of the porter with the dismal covered trolley on which the body is removed. In circumstances such as these little sleep can come to the other patients, as they lie awake with straining, horrorstruck eyes which gaze timidly about to see what the others are doing and how they are taking it. Imagine the psychological effect of all this upon a nervous individual fighting for his own life and health in a near-by bed-nothing could be more cruel, more unnecessary, or worse, medically, than to subject him to such an ordeal.

\section{Operation Cases in the WaRds}

There is another feature of our hospitals to which we are equally callous-namely, the admission of a young and inexperienced man, about 18 years of age, into a surgical ward preparatory to an operation, say, for hernia. He enters a strange building where, after a wait of variable length, he is shown up into a ward. He is not ill, but he is told to undress and get into bed. Like the new boy at school, he knows no one, and understands little of his surroundings. He notices that there is a curious arrangement like a small house under the blankets of the next bed, which at the moment is empty. A nurse may come from time to time to examine it, and he sees that the houselike contrivance is full of electric lights over which the bedclothes are draped, and he wonders what all this is for. Presently steps are heard coming along the corridor and the door is bumped open by the end of a trolley pushed by a porter. The nurse wh:sks away the small house, and arranges the bedclothes as the trolley is brought alongside the bed and a groaning patient is transferred from the trolley to the bed next to him. A transferred from the trolley to the head of the patient, and an ominous-looking basin placed near at hand. Then the ominous-looking basin placed near at hand the sights
ordeal begins. The new patient is horrified at the and sounds that follow-the groaning, the incoherent talk, the vomiting, and all the disgusting features of a patient, his actions shorn of human semblance, slowly regaining consciousness after an operaticn. Timidly he may inquire. what it is all about, and a nutse may inform him shortly that it is only a case of hernia which has been operated on that afternoon. Only a case of hernia! $\mathrm{He}$ is a hernia case too!. But this may not be all; the surgeon of the ward may be operating that day, and three or four similar cases may be placed in the same ward that afternoon-perhaps a case operated upon for tonsils and adenoids, in which the sight of quantities of blood-stained expectoration are added to the other horrors. Is the new patient, in this environment, likely to horrors. Is the new patient, in that must be his thoughts of his cwn approaching ordeal? I have instanced a case of his cwn approaching orderious effect would be multiplied a thousandfold, and might assume serious features, if the case was one of exophthalmic goitre awaiting operation.

When I hear some of the leaders of our profession speak proudly of the march of science and the progress of medicine, and lay. stress on the growing importance of psychology, I sometimes wonder if their tongues are in psychology, I for they must know the two scenes I have endeavoured to depict are everyday occurrences in the wards of their own hospitals.

$$
\begin{gathered}
\text { The Remedy-“ Death Room " and “ Recovery } \\
\text { Ward " }
\end{gathered}
$$

Now let me deal with the remedies for these two anachronisms which, now they are pointed out, will, I hope, soon become customs of the past.

In the first place, each hospital should provide one or two small wards into which a person about to die can be removed. This should be insisted upon both for the convenience of friends and relatives and even more so in the interests of the other patients. During the war I organized three hospitals, and in each a ward for the dying was provided. I never saw wards for the dying provided in any military hospital except my own, but I have heard that something approaching them was arranged at Salonika: It might be argued that the act of being transferred to the ward for the dying might have 
a detrimental effect on the patient. A moving picture of such an occurrence is portrayed in the novel All Quiet on the Western Front. To me, with experience in this matter, the scene was totally false ; the patient was never removed unt:l he had lost sense of his surroundings. Incidentally, it showed that the need for such wards was recognized even in the German hospitals, where we should hardly look for sentimentalism. In Archangel, during the 'flu epidemic, we had a ward of sixteen beds set apart for such cases, and for a time it was almost continually filled. I only knew of one mistake being made, where the man actually lived and returned to the general ward. Being a bit of a " wag," he never failed to make reference to his little excursion when I made my rounds.

To remedy the second state of affairs recovery wards should be provided, where patients recovering from the effects of the anaesthetic can be nursed till the disagreeable effects have passed off. Most of them could be returned to the general wards in twenty-four hours, and the worst cases would only remain in the recovery ward for two, or at the most three, days. When the new Freemasons' Hospital was being built I strongly recommended the provision of these recovery wards of six beds for each sex-a low partition between each bed, with, perhaps, a curtain at the foot to make supervision easy. To the patient in his semi-conscious condition, with the senses dulled by morphine, h:s surroundings would not matter, and he would not be made more miserable by the presence of neighbours in like state. I could not, however, get all the surgeons to agree upon the subject, and some to whom the idea was new said they much preferred their patients to be nursed in the wards in which they would subsequently lie. The point of view of the other patients did not appeal to them. Nevertheless, the suggestion was considered by the building committee, who have wisely set aside small wards for this purpose and, although they are not quite what was originally suggested, their value is already appreciated.

\section{OTHER REFORMS}

There are other, but perhaps less important, reforms needed in our hospitals. To my mind it is pathetic to see patients sitting in low chairs eating meals from high bedside tables, or, still more inappropriately, from their beds. A dining room should be provided for those who are up and about, or, failing this, there should be a central table in the ward at which they could have their meals. Some of the features of a hydropathic establishment are sadly needed in our hospitals, for what is useful in one establishment would be equally useful in the other. The next suggestion, which obviously goes with the last, is the provision of a sitting room, reading room, or library, where papers, periodicals, and books are provided. He who wishes to cavil at these suggestions may say that the pressure on our large hospitals is such that we do not have convalescent cases. Such, however, is not the case, for at least 10 per cent. of the patients could get up if there was room for them. In our present hospitals the provision of space for these changes is almost impossible. I am, however, speaking of the hospital of the future, where provision could and should bet made for these improvements.

Another necessary feature sadly wanting in many hospitals is the provision of a good convalescent home. A hospital without a good convalescent home is like a man with one leg. By a convalescent home I do not mean a place where a patient is sent to and lost sight of, but somewhere where he can convalesce after his operation. After the seventh or, at the most, the tenth day, a case operated on for hernia occupies a bed and needs little attention. He could quite well be looked after in a convalescent home. Most of the so-called convalescent homes to which patients are now sent are merely boarding establishments, with no resident med:cal staff. There is usually a proviso that the patient must be able to get up and about and must not require any dressings; no medical treatment can be undertaken, and there is no touch with the establishment from which the patient came, except through the almoner who arranges the admission. It is to these establishments that the term " convalescent home" is now applied.

A definite feature of every hospital should be an efficient follow-up system. It is only needed for a very few diseases, but they are of vast importance, and inclucie all slowly fatal ones-chiefly blood and lymphatic diseases -and all forms of malignant disease. It would, perhaps, be best for the follow-up system to be under the management of the public health authorities, so as to ensure uniformity, efficiency, and the collection and good use of the statistics produced. The notes of the patient would follow him from institution to institution if necessary. The follow-up department would keep in touch with the patients, who would report themselves at certain times. There are most excellent follow-up departments in connexion with the cancer institutes on the Continent, and we have copied them at our cancer centres, though it seems more difficult here to make the patient see the importance of this department. In Sweden free railway tickets are issued to patients who wish to report at the centres. The follow-up system also keeps the hospital in touch with the general practitioner who supervises the patient at his home.

\section{Future Developments}

There are many reasons why the ideal hospital will not be built in this country for some time to come, for we have become wedded to two opposing systems-(1) the voluntary hospital, which prides itself on its efficiency and advertises its unbusiness-like behaviour by exaggerating its debts in the hopes that it will thereby appeal more strongly to the generosity of the public ; and (2) the municipal hospital, recently brought up to date by the Board of Health, under the skilful guidance of Sir Frederick Menzies. From now on the latter type of hospital is going to be an efficient and serious rival of the voluntary hospital for public favour. This is already recognized by the voluntary hospital ; considerable jealousy has been evinced, and the medical profession has even been induced, half-heartedly, to take sides. Neither side is likely to scrap its methods, but the bringing up to date of the municipal hospital is going to have a far-reaching effect on the voluntary hospital, and whether the voluntary hospital will survive remains to be seen. If in the future the Government were to take over the whole hospital system of this country they would have central purchasing boards for food, dressings, drugs, and equipment, and a great saving would result. Such central boards could be introduced now with the same advantages if the hospitals could be induced to combine. At the moment many of the voluntary hospitals cannot provide the equipment specified by the staff as they cannot find the money, and some of the reforms mentioned cannot be introduced for the same reason. It is perfectly possible to visualize a fusion of the two systems at some future time, simply because many voluntary hospitals may not be able to compete with the Government establishment, where everything would be provided. Thus the municipal hospital may become the more favoured by the public.

Where does the opposition to fusion come from at the present moment? Partly from the leaders of the medical profession, many of whom are conservative in outlook and do not take readily to new ideas. What is the attitude of the younger men? Have they shown any repugnance to entering the service of the municipal hospital and being paid for the services they render to the State? Not at all ; they clamour for the posts. The cay of the honorary staff is passing. The pressure of life and taxation is rendering it impossible for a medical man to give his services for nothing in the way he used to do. He should be the last to regret the change. Far more serious opposition will come from the Government. who will not want the added expense or the responsibility. If charitable people will provide the money, it is unlikely that the Government will wish to shoulder the burden, though the Government has built and staffed nearly all the hospitals in our Crown Colonies. They are, incidentally, excellent institutions. 
Alongside the general hospitals, voluntary and municipal, and perhaps because of them, there will appear another sort of hospital for the better-class patient. These private hospitals ought to cater for the middle class and contain private rooms and small wards for two, four, six, or eight patients according to their means, wards for the dying, recovery wards, dining rooms, and reading rooms. Few people really object to small wards. The upper middle classes, as represented by officers in His Majesty's services, are provided with wards in Millbank Hospital if they are under field rank, and a very well run private hospital for officers does the same thing for nearly all ranks. This also is the experience of anyone who has worked in large nursing homes where small wards are provided-they have been the greatest success in the Freemasons' Hospital.

Doubtless there will be fashionable institutions run by titled ladies with a gift for nursing or management, and in $\mathrm{my}$ experience these places are run with remarkable efficiency-their vogue would not endure long if they were inefficient. Smart society and the plutocracy would insist upon admission. There would be no difficulty in making prices to correspond in every way.

\section{SILICOSIS : RIVAL THEORIES}

The discussion on silicosis, held under the auspices of the Institution of Mining and Metallurgy, of the first part of which some account appeared in the Journal of February 10th (p. 254), was completed on February 15th. It was noteworthy for a brisk exchange between Professor J. S. Haldane, who holds the view that the cause of silicosis is a dust with a high percentage of quartz, and Mr. W. R. Jones, D.Sc., of the Royal School of Mines, who maintains that it is the minute acicular fibres of sericite.

At the resumed meeting Professor S. Lyle Cummins sent a communication stating that the information which Dr. Jones had collected about the distribution of sericite in rocks and its close correspondence with the distribution of silicosis had brought to the problem of pneumoconiosis an entirely new concept, which fitted in better with the observed facts than that based on the theory that what was called silicosis was due entirely to free silica. Those who had studied the problem in the South Wales coalfield, said Professor Cummins, had always been conscious of the underlying uncertainty as to how some of the miners had managed to breathe in sufficient free silica to explain the condition found. The possibility that it was combined silica which was causing the damage was now supported by very convincing evidence, and he for one was deeply impressed by Dr. Jones's findings. $\mathrm{He}$ suggested that they might be finally established by the production of experimental silicosis in animals by means of sericite.

On the other hand, Dr. S. W. Fisher, medical inspector of mines, said that he still adhered to the view that silicosis was a pathological condition of the lungs due to the inhalation of silicon dioxide in a chemically uncombined state. To his mind the evidence regarding the danger of the inhalation of dust containing a high percentage of free silica was overwhelming; whether sericite played a part in this remained to be proved. Dr. J. S. Owens also contested some of $\mathrm{Dr}$ ، Jones's conclusions, and said that he felt that. Dr. Jones had not advanced any acceptable proof of the absence of large numbers of very fine quartz particles from the air of mines where silicosis was common-that is, particles well below one micron in diameter. He considered that the presence of sericite fibres and the absence of silica from the lung tissues which Dr. Jones had examined might be due to the greater solubility of the silica, and did not necessarily mean that sericite was the cause of the disease present.

\section{Measures for Prevention}

A good deal of the discussion was occupied with measures for the prevention of silicosis. Dr. Jones had put forward a twofold proposal: that the less mobile workers should be provided with a light cover for the mouth and face and a supply of fresh air from compressedair pipes, and that the more mobile workers should be provided with a supply of compressed air carried on their backs ; but Mr. F. H. Wynne, deputy chief inspector of mines, considered that very few coal miners in this country could be included in the first category, and as regards the self-contained supply from a cylinder, he was very doubtful as to its practicability. The better way was to attack the dust either at its source-the borehole, for example-or, in so far as that was not possible, by means of respirators. He said that the method of extracting dust before it reached the atmosphere, by means of a so-called dust-trap, and depositiog it in a filter, was now largely employed in South Wales. Professor B. W. Holman, however, suggested that the provision of a separate supply of air for each man was not so impracticable as it sounded, and according to some calculations he gave, it worked out at one penny per hour per man.

Professor Haldane said that he looked for a remedy in the stone-dusting of a dangerous mine with a dust which would sufficiently dilute the free silica. Other speakers suggested a reinvestigation of ventilation in mines, the possibility of blanketing the fine dust after it had settled by a layer of innocuous dust, or the addition of a chemical to the water spray to assist in wetting the sericite (supposing that to be the culprit), sericite being not easily wetted by water alone. Professor J. G. Lawn, as one intimately concerned with silicosis-prevention in South Africa, spoke of the disappointing results there. Nearly twenty years ago the Miners' Phthisis Prevention Committee in South Africa succeeded in laying 97 or 98 per cent. of the dust, but no very striking diminution of silicosis incidence had followed, although in addition to laying the dust other hygienic measures had been taken, and it had been ensured that only healthy workers were recruited. It was mentioned by another speaker that the incidence of new cases in South Africa was now slightly under 2 per cent. per annum, as compared with about 2.6 per cent. some ten years ago.

Dr. Jones, in replying to the discussion, warmly defended his hypothesis. He quoted the figures recently given in Parliament showing that while the South Wales coalfield employed only 18 per cent. of the coal miners in this country, it accounted for 89 per cent. of the cases of silicosis. Dr. Jones contended that the bulk of these cases came from a localized anthracite area, where sandstones occurred just above or just below the coal seams, and these and the sandy shales had been shown to contain myriads of minute fibres and scales of sericite. In the Scottish coalfield, on the other hand, where there were few cases of silicosis, the sandstones contained very few such fibres.

The fourth International Congress on Rheumatism will be held at Moscow, May 3rd to 6th, 1934. The following subjects will form the basis for discussion: (1) the problem of the clinical aspects of rheumatic fever ; (2) indications for the balneological treatment of rheumatic patients; and (3) social and occupational aspects. Among other speakers Dr. G. P. Cawadias will contribute to a discussion on metabolism in rheumatism; Dr. B. Schlesinger, on clinical aspects of rheumatic fever in children; and Dr. R. Fortescue Fox, on balneological treatment. There are two ways of travelling in order to attend the congress. (1) To take a three-week tour (giving twelve days in Russia), leaving London on April 21st for Leningrad, by boat, and then on to Moscow ; the inclusive cost of this (boat and railway travel and hotels) is $£ 23$ third class, $£ 38$ second class. (2) Those who have less time can travel overland via Harwich, The Hook, Berlin, Warsaw, Negoreloje, to Moscow ; the return ticket from London to Moscow is $£ 46$ first class, $£ 36$ second class with sleepers, $£ 28$ 10s. second class without sleepers, $£ 19$ third class. Accommodation in the U.S.S.R., by the day (covering all expenditure), costs $£ 3$ first class, $£ 115 \mathrm{~s}$. second class, $£ 15 \mathrm{~s}$. third class. Further information can be obtained from the secretary, S.C.R., 1, Montague Street, W.C.1. 